\title{
Prevalence and genetic variability of Anaplasma phagocytophilum in wild rodents from the Italian alps
}

\author{
Fausta Rosso ${ }^{1 *}$ DD, Valentina Tagliapietra', Ivana Baráková ${ }^{1,2}$, Marketa Derdáková ${ }^{2}$, Adam Konečný1,3, \\ Heidi Christine Hauffe ${ }^{1}$ and Annapaola Rizzoli ${ }^{1}$
}

\begin{abstract}
Background: Human granulocytic anaplasmosis is a zoonotic bacterial disease with increasing relevance for public health in Europe. The understanding of its sylvatic cycle and identification of competent reservoir hosts are essential for improving disease risk models and planning preventative measures.

Results: In 2012 we collected single ear biopsy punches from 964 live-trapped rodents in the Province of Trento, Italy. Genetic screening for Anaplasma phagocytophilum (AP) was carried out by PCR amplification of a fragment of the 16S rRNA gene. Fifty-two (5.4\%) samples tested positive: 49/245 (20\%) from the bank vole (Myodes glareolus) and 3/685 (0.4\%) samples collected from the yellow-necked mouse (Apodemus flavicollis). From these 52 positive samples, we generated 38 groEL and $39 \mathrm{msp} 4$ sequences. Phylogenetic analysis confirmed the existence of a distinct rodent strain of AP.

Conclusions: Our results confirm the circulation of a specific strain of AP in rodents in our study area; moreover, they provide further evidence of the marginal role of A. flavicollis compared to M. glareolus as a reservoir host for this pathogen.
\end{abstract}

Keywords: Anaplasma phagocytophilum, Ear biopsy, msp4, groEL, Myodes glareolus, Apodemus flavicollis, Phylogenetic analysis

\section{Background}

Anaplasma phagocytophilum (AP) is a gram-negative bacterium transmitted by ixodid ticks, mainly by Ixodes ricinus in Europe [1, 2], although I. tranguliceps may play a critical role in the sylvatic cycle [3]. This zoonotic pathogen, reported from about 100 species of vertebrates worldwide [4], is responsible for anaplasmosis in livestock and companion animals and therefore is of recognised veterinary relevance. AP also causes human granulocytic anaplasmosis (HGA), an emerging human disease of public health concern $[5,6]$. AP primarily invades and replicates in polymorphonuclear leucocytes and usually causes influenza-like symptoms in humans, although infection is occasionally fatal [7]. The epidemiological cycle of

\footnotetext{
* Correspondence: fausta.rosso@fmach.it

${ }^{1}$ Fondazione Edmund Mach, Research and Innovation Centre, San Michele all'Adige, TN, Italy

Full list of author information is available at the end of the article
}

this pathogen in Europe is poorly understood but is likely complex given a large number of possible reservoir hosts, the broad distribution and extensive niches of tick vector species and the various bacterial genotypes identified [6].

In Italy, as in the rest of Europe, the majority of studies on this pathogen have focused on the screening of the main tick vector, $I$. ricinus, with prevalence in engorged ticks ranging from 1 to $20 \%$ in Europe (see [4] and references therein) and from 4.4\% (Province of Belluno [8]) to $24.4 \%$ (Region of Lazio [9]). Other European studies have confirmed AP infections in medium-sized and large wild mammals, such as roe deer, red deer, wild boar and red fox $[2,10]$ as well as in companion animals, like dogs, horses and domestic ruminants $[4,11,12]$. Very little is known about the role of passerine or migratory birds as competent reservoirs or as tick dispersers [13, 14], although Jahfari et al. [1] recently reported that AP genotype IV tends to be associated with bird species. This genotype 
has not been detected in other vertebrates or questing I. ricinus ticks [1].

Here we focus on the role of small mammals, which are well-known reservoirs of many tick-borne pathogens, but also crucial feeding hosts for various stages of I. ricinus [15]. Recent observations from central and western Europe, including Italy, suggest that small mammals may have independent epidemiological cycles involving genetically distinct, non-pathogenic AP genotypes [16-18]. In this study we use a collection of tissue samples from live-captured animals in four study sites at two different altitudes in the Province of Trento, Italy, to investigate AP genotypes circulating in rodents in more detail. A large number of PCR positive samples allowed us to confirm the existence of distinct AP strains associated with rodents. Moreover, we extended the knowledge on AP prevalence in rodents in this area.

\section{Results}

Four rodent species belonging to A. flavicollis $(n=685)$, M. glareolus $(n=245)$, A. sylvaticus $(n=28)$ and Microtus multiplex $(n=6)$ were captured. Ear biopsies from all 964 individuals were screened for AP. Fifty-two rodents tested positive with an overall PCR prevalence of 5.4\% (52/964, 95\% CI: 3.97-6.83\%); ranging from $0 \%$ for $A$. sylaticus and $M$. multiplex to $0.4 \%(3 / 685 ; 95 \%$ CI: $0.07-0.87 \%)$ for A. flavicollis and $20 \%(49 / 245$; 95\% CI: 9-31\%) for M. glareolus. The difference in prevalence among the two most represented species, A. flavicollis and M. glareolus, was statistically significant $\left(\chi^{2}=130.82, d f=1, P<0.0001\right)$, with more PCR-positive bank voles than yellow-necked mice. Only rodents trapped at high altitude study sites were positive for AP (Table 1). The ratio of captured rodent species also differed greatly at the two altitudinal levels with $301 \mathrm{~A}$. flavicolllis and $3 \mathrm{M}$. glareolus at the lower altitude sites (100 to 1), and 384 and 242, respectively, at the higher altitude sites (1.5 to 1). AP prevalence between species in the two positive sites was compared, but no statistical differences were observed (Fisher's exact test, $P>0.01$ ).
A total of 1746 ticks (1717 larvae; 29 nymphs) were counted on rodent hosts (see Table 1). Apodemus flavicollis hosted a higher number of ticks $(n=1526)$ compared to M. glareolus $(n=220)$ (Fisher's exact test, $P<0.0001)$. The mean and total number of ticks hosted by rodents was higher at low altitude study sites (mean $=3.86 ; n=1142$ ) compared to high-altitude sites (mean $=0.97 ; n=604$ ). The 11 specimens of I. trianguliceps ticks were collected from the yellow-necked mouse and the bank vole species and were represented by 1 larva, 6 nymphs and 4 adults.

Two hundred and fifty-one animals out of 930 (27\%) from this study were screened for the presence of AP in blood pellets in the previous work [18]. One animal tested positive in both ear and blood samples, while 12 animals previously negative on a blood sample, now tested positive on ear punch sample.

The partial 16S rRNA gene was sequenced for all 52 positive PCR products and confirmed as AP. From these, we also obtained $39 \mathrm{msp} 4$ and $38 \mathrm{groEl}$ sequences. The mean nucleotide diversity $(\pi)$ among the $A$. phagocytophilum sequences was 0.073 (range 0-0.161) for msp4 and 0.034 (range 0-0.192) for groEL. The maximum likelihood phylogenetic trees for the two partial genes, including previously published reference samples [18], and available sequences from the GenBank database, had similar topologies and consisted of two main clades (Fig. 1). The first clade included haplotypes detected in questing $I$. ricinus ticks and various vertebrate hosts such as deer, birds, domestic sheep, domestic dogs and humans from various European countries and the USA. The second clade included only haplotypes from feeding I. trianguliceps from Slovakia, as well as rodents and insectivores from various EU countries. Specifically, all groEL sequences generated here, regardless of rodent host species, were $100 \%$ identical to groEL sequences of AP from blood samples of bank voles from Italy (GenBank: KF031390) and 99\% to groEL sequences of AP extracted from I. trianguliceps feeding on voles from Slovakia (GenBank: KF383233, KF383235) [17, 18] (Fig. 1a). The msp4 representative sequence was $100 \%$ identical with that from blood samples of bank voles from Italy (Genbank: KF031422-KF031424, KF031426) and the UK

Table 1 Total and average number of ticks by stage, counted on rodent species in the high and low altitude sites in 2012 (Province of Trento, Italy)

\begin{tabular}{|c|c|c|c|c|c|c|}
\hline \multirow[b]{2}{*}{ Species } & \multicolumn{3}{|l|}{ High altitude sites } & \multicolumn{3}{|l|}{ Low altitude sites } \\
\hline & $\begin{array}{l}\text { Total no. of larvae } \\
\text { (Mean) }\end{array}$ & $\begin{array}{l}\text { Total no. of nymphs } \\
\text { (Mean) }\end{array}$ & $\begin{array}{l}\text { Total } \\
\text { (Mean) }\end{array}$ & $\begin{array}{l}\text { Total no. of larvae } \\
\text { (Mean) }\end{array}$ & $\begin{array}{l}\text { Total no. of nymphs } \\
\text { (Mean) }\end{array}$ & $\begin{array}{l}\text { Total } \\
\text { (Mean) }\end{array}$ \\
\hline Apodemus flavicollis & $383(0.99)$ & $2(0.005)$ & $385(1)$ & $1124(3.84)$ & $17(0.06)$ & $1141(3.89)$ \\
\hline Myodes glareolus & $209(0.87)$ & $10(0.04)$ & $219(0.91)$ & $1(0.33)$ & 0 & $1(0.33)$ \\
\hline $\begin{array}{l}\text { Total no. of ticks } \\
\text { (Mean) }\end{array}$ & & & $604(0.97)$ & & & $1142(3.86)$ \\
\hline
\end{tabular}




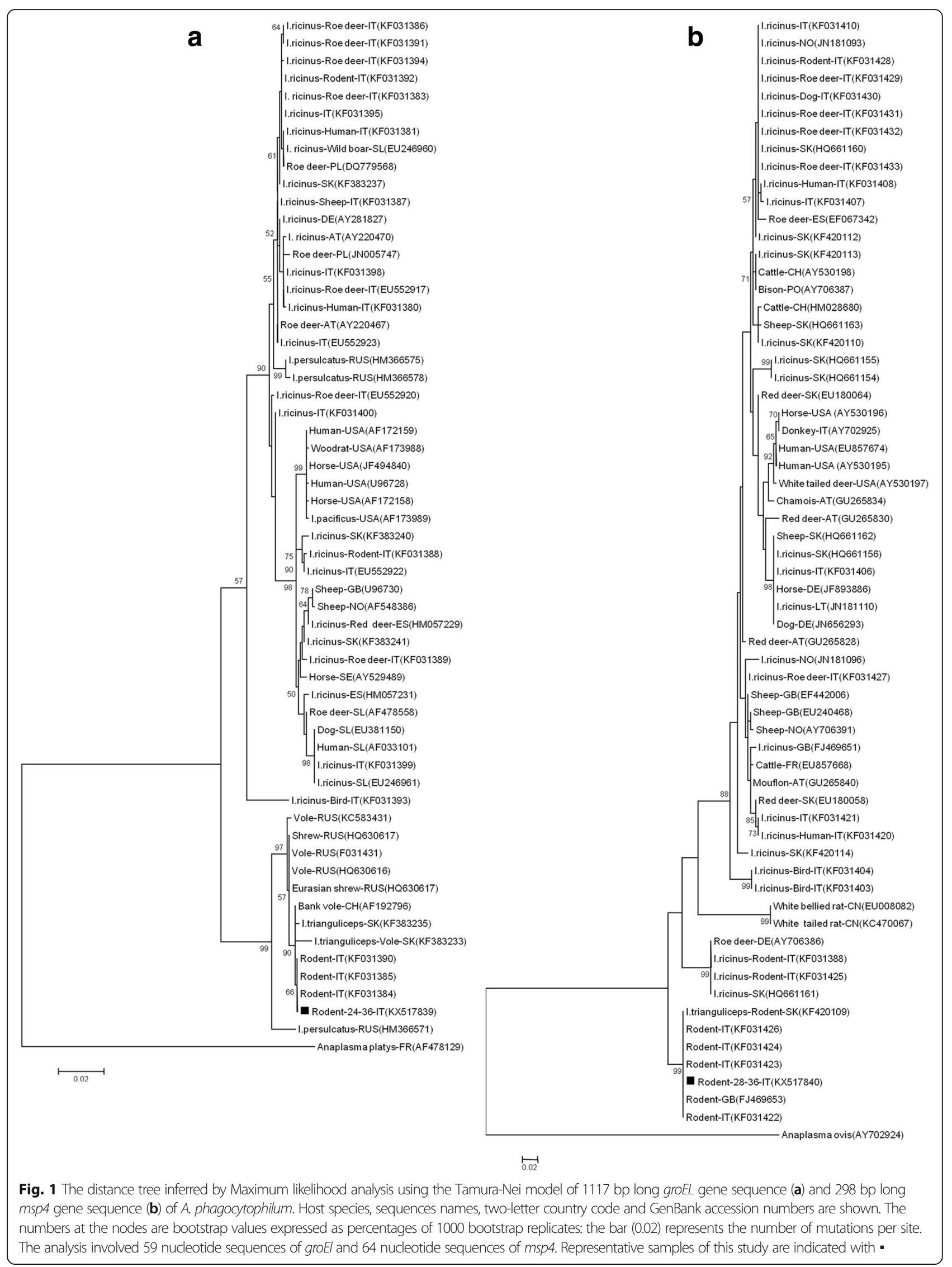


(GenBank: FJ469653), as well as from $I$. trianguliceps feeding on rodents from Slovakia (GenBank: KF420109) [16-18] (Fig. 1b).

\section{Discussion}

Understanding the natural infection cycle of AP is complicated by the presence of several genetic variants carried by some tick vectors feeding on a variety of vertebrate host species. HGA cases are the third most common tick-borne human diseases in USA and Europe [19], although European cases are less severe than Asian and North American ones [20, 21]. Not all AP genetic variants identified are pathogenic to humans, and even if several variants may coexist in the same geographical area, they appear to have distinct enzootic cycles $[1,16,22]$. For example, in the eastern USA, $I$. scapularis hosts both the Ap-V1 non-pathogenic variant as well as Ap-ha pathogenic variant; however, among vertebrates, Ap-V1 is only found in the whitetailed deer (Odocoileus virginianus) [23], while Ap-ha only in the white-footed mouse (Peromyscus leucopus) [24].

In Europe, several studies have confirmed the importance of $I$. ricinus as a vector of AP [4] and the role of small mammals in maintaining the immature stages of this tick $[17,25,26]$. However, AP infection prevalence in rodents varies considerably between studies and rodent species [4]. A recent phylogenetic analysis suggested that the rodent AP strains belonged to a different cluster to that of other mammals and involved another tick species, I. trianguliceps [1]. For this reason, we performed our analysis on a large rodent dataset to improve our knowledge of a possible independent epidemiological cycle for same AP genotype.

In a previous study, we presented an assessment of the circulating genotypes of AP in the rodents in the Province of Trento, using blood samples [18]. The overall prevalence in 1295 animals (A. flavicollis, Moscardinus avellanarius and $M$. glareolus) was $0.3 \%$ (4/1295), but only bank voles were positive (4/100; $4 \%)$. In this study, the overall prevalence was $5.4 \%$ (52/964). Bank voles were $20 \%(49 / 245)$ PCR-positive and yellow-necked mice $0.4 \%$ (3/685). Similar results for AP prevalence in bank voles have been obtained across Europe; for example, $19.2 \%$ in Switzerland from blood and tissue samples [25], 3.6-20.5\% in Slovakia from ear and spleen samples [17], $13.8-23.1 \%$ in France from blood and spleen samples [27] and 22\% in Finland from blood samples [28]. To increase the number of bank voles we included sites above $1000 \mathrm{~m}$ asl. In fact although this species is well represented in temperate woodlands, it becomes scarce in Mediterranean areas, its southern limit of distribution, where it is influenced by tree cover and height, the presence of dead vegetation, moss and rocks, and moist woodlands [29]. In our study area, these characteristics are satisfied above $1000 \mathrm{~m}$ asl where the climate is classified as alpine-continental with an average annual temperature around $8-9{ }^{\circ} \mathrm{C}$ and $1000-1500 \mathrm{~mm}$ precipitation [30].

In this study, 251 animals screened using ear biopsies were previously PCR-screened from blood pellets in Baráková et al. [18]. Twelve animals testing negative in blood samples tested positive from ear punch samples posing concerns about PCR sensitivity or which sample is better to test. Therefore, possible reasons for these results could be that 1) AP infection in the peripheral blood stream of rodents seems to be short-lived [3, 25, $26,31,32]$; 2) at the onset of infection the pathogen stays in the peripheral blood before spreading to the overall circulatory system, similar to other tick-borne pathogens [33], but the detection level of AP DNA in blood of non-immune animals reaches and exceeds the threshold of PCR sensitivity only a few days after tick detachment [34]. Since ear biopsies are a less invasive biological sample yet more efficient in the detection of AP compared to blood or organs collection in rodents, we conclude that ear biopsies should be used in the future for screening AP whenever possible.

Our study presents a phylogenetic analysis of the largest number of AP sequences from rodents thus far. The use of specific molecular markers has recently helped to discriminate between genotypes and revealed the existence of an independent epidemiological cycle involving rodents as reservoir hosts, the tick I. trianguliceps as a vector $[16,17]$ and a non-pathogenic AP strain. The groEL and msp4 sequences generated in this study (Fig. 1) confirm that a single rodent AP genotype circulates in Italy, distinct from the strains found in other hosts, as previously suggested by Bown et al. [16] and by Baráková et al. [18]. This genotype is also identical to those reported from the UK in the field vole (Microtus agrestis) and bank vole [3], and in Slovakia in the yellow-necked mouse and I. trianguliceps [17].

Among all the questing and feeding ticks screened for the presence of AP in our previous study [18], only $I$. ricinus tested positive, and the AP genotype was different from that found in rodents $[6,16-18,26]$. In this study the number of ticks counted on the rodents was higher at low altitudinal level (Table 1), in particular on the yellow-necked mouse. Other authors in Europe reported a higher infestation rate of I. ricinus on Apodemus species compared to M. glareolus [35-38] although some exceptions are noted [39-42]. The role of I. ricinus as important vector of rodent AP infections in continental Europe has been described [25], but evidence showed that if only this species is present, AP cannot be maintained in woodland rodent communities, on the contrary, this is achieved where $I$. trianguliceps is also present $[3,26]$. In addition, no efficient transmission of AP to I. ricinus 


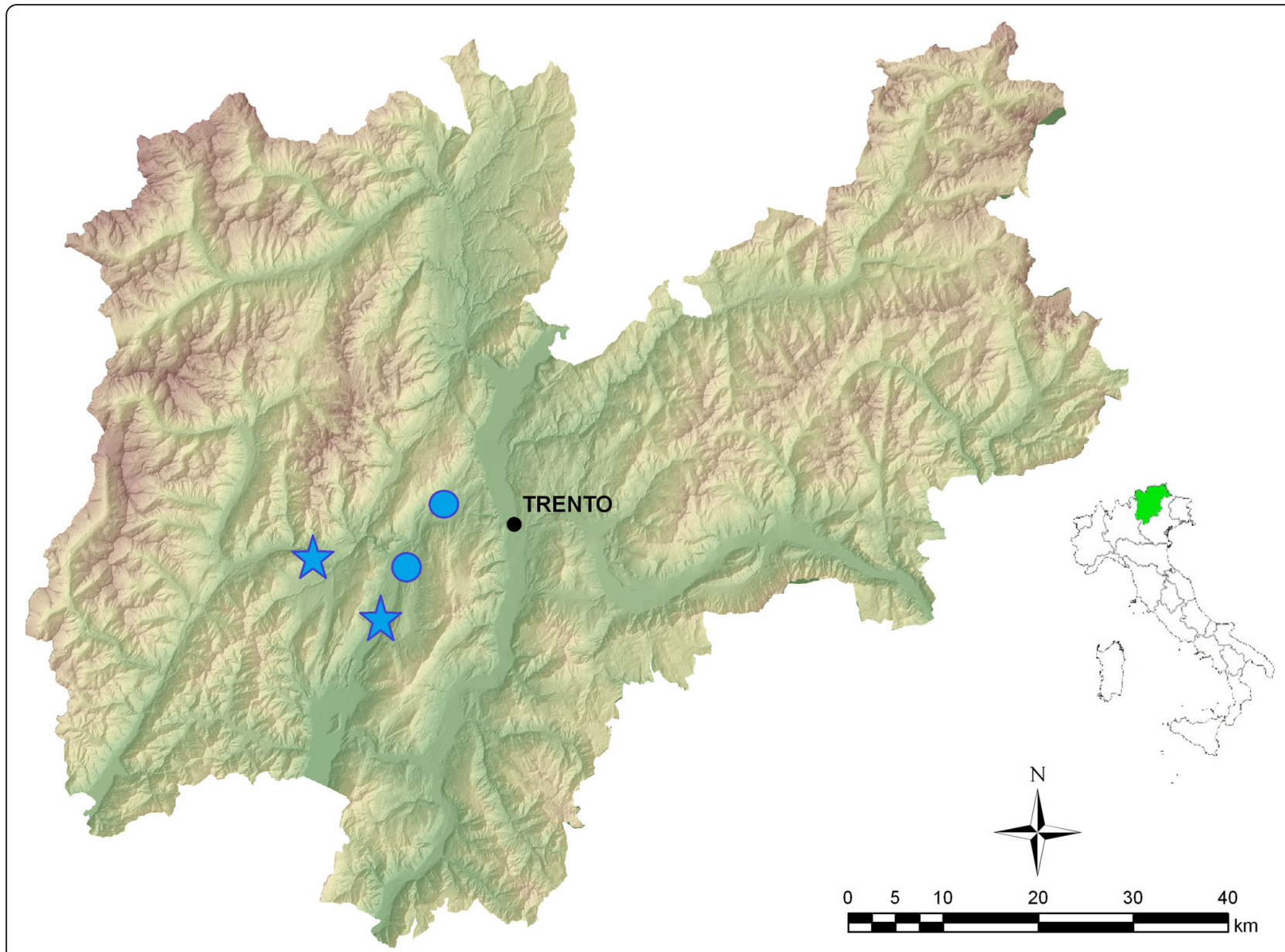

Fig. 2 Map of the Province of Trento, Italy, showing the position of the rodent sampling sites (stars indicate high altitude sites; circles indicate low altitude sites). Map is a high-resolution digital elevation model $(10 \mathrm{~m})$ and land use map both provided by the "P.A.T. S.I.A.T." service of the Province of Trento

larvae under laboratory conditions has been confirmed using field-captured tick-infested rodents [43]. Although some authors reported the presence of a small proportion of infected I. ricinus larvae, supporting the hypothesis that all three tick stages are involved in AP transmission [1, 32, 44], this mode remains minor and needs to be further investigated. The presence of I. trianguliceps has been recently confirmed in northern Italy [18]. I. trianguliceps, also known as vole tick, is endophilic, host specialist, non-questing and usually present at very low level on its rodent host [3, 45]; for these reasons chances of contacts with humans are unlikely. Nonetheless, the main concern is that the sympatric presence of both specialised and generalised species has been shown to have a role in maintaining a high level of infection on rodent hosts $[1,3,46]$. In our specific context, I. trianguliceps may be important in maintaining high infection levels in the reservoir hosts with regards to Babesia microti and Anaplasma phagocytophilum [1, 3, 47]. Moreover, due to the complexity of interactions between ticks, vertebrates and associated pathogens, the enzootic infections maintained in an I. trianguliceps-rodent cycle could escape into other hosts, including humans [3].

\section{Conclusions}

Using a high number of positive rodent samples and sequenced partial genes than previous studies we have shown that in the Province of Trento, Anaplasma phagocytophilum is present and circulates predominantly among rodents, especially bank voles, with a distinct enzootic cycle. The presence of the tick species, I. trianguliceps, could not be quantified. The strain of AP found in rodent ear punches in this study was $100 \%$ identical to that found in rodents and I. trianguliceps reported in other European studies. From an infectious control perspective, it is important to clarify the role of small mammals in the transmission cycle of Anaplasma phagocytophilum and the role of other tick species in maintaining high infection levels in the reservoir hosts 
and acting as possible bridging vectors for the rodent genotype toward humans or domestic animals.

\section{Methods}

\section{Study sites and rodent sample collection}

Small rodents were live-trapped in the Province of Trento, Italy, from April to October 2012 using multiple-capture Ugglan live traps (model 2, Granhab, Sweden), set in $8 \times 8$ square array grids with a $10 \mathrm{~m}$ inter-trap distance. Four grids were set at each of four locations in beech forests where both rodents and ticks are common: two locations were at $700 \mathrm{~m}$ above sea level (asl) and two at $1200 \mathrm{~m}$ asl (Fig. 2). Each individual was tagged with a subcutaneous passive integrated transponder (pit-tag ID100 Trovan ${ }^{\circ}$, UK) to ensure that each individual was identifiable and only sampled once. We routinely counted ticks on hosts, represented mainly by the larval stage, but did not remove them, so the identification with the naked eye at species level was not possible and therefore we cannot assess the proportion of the two feeding tick species. For the presence and identification of Ixodes species on rodents, we refer to the previous study described in Baráková et al. [18], where some tick specimens were randomly collected from the animals and genetically identified, contributing to the first record of I. trianguliceps in the Province of Trento. An ear biopsy was taken at first capture using sterile disposable ear punch needles $(\varnothing 3 \mathrm{~mm})$, and samples were stored individually and frozen at $-80{ }^{\circ} \mathrm{C}$ until analysis. Since both $A$. flavicollis and A. sylvaticus occur in sympatry in the Province of Trento and are not reliably identifiable by eye, we confirmed that all Apodemus captured were A. flavicollis following Michaux et al. [48]. Of the 930 animals screened using an ear biopsy in this study, 251 were previously screened for the presence of AP in blood pellets [18].

\section{Anaplasma phagocytophilum detection}

DNA was isolated from each ear biopsy using the DNAeasy blood and tissue kit (Qiagen, Hilden, Germany) according to the manufacturer's protocol. The presence of AP was detected by amplifying 546 bp of the $16 \mathrm{~S}$ rRNA gene using a nested PCR with primers ge3a/ge10r and ge9f/ge2 after [49]. A reaction without template (water added) served as negative control while AP-DNApositive amplified from $I$. ricinus was used as positive control. Positive PCR products were purified using Pure Link quick gel extraction and PCR purification combo kit (Invitrogen, Thermo Fisher Scientific Baltics, Lithuania) and sequenced using the primers listed above. A BLAST search was performed for all sequences. For AP positive samples, variable partial genes, $m s p 4$ and groEL were amplified and sequenced as already described in $[50,51]$.

\section{Statistical and phylogenetic analysis}

Fisher's exact test or Chi-squared tests were carried out to determine if there were statistical differences in the prevalence of AP between the two main rodent hosts and among sites and altitudes.

Nucleotide sequences were verified using Sequencer 4.7, assembled using MEGA6 software and further aligned with ClustalW [52]. The alignment showed that all samples from this study were $100 \%$ identical. Therefore only one representative sequence was used for subsequent phylogenetic analysis. MEGA version 6 was used to construct a phylogenetic tree for each gene fragment (Fig. 1) [52]. The maximum-likelihood algorithm [53] with Tamura-Nei model [54] were used with Felsenstein's [55] bootstrap test of 1000 iterations. The analysis involved 59 nucleotide sequences of $g r o E l$ and 64 nucleotide sequences of $m s p 4$ downloaded from NCBI and 1 representative groEL and msp4 nucleotide sequence from this study (GenBank Accession nos. KX517839 and KX517840, respectively).

\section{Abbreviations \\ AP: Anaplasma phagocytophilum; Asl: above sea level; HGA: human granulocytic anaplasmosis}

\section{Acknowledgements}

The authors thank all field assistants from the Department of Biodiversity and Molecular Ecology at the Fondazione E. Mach where the sampling was carried out. Laboratory work was performed partly at F. Edmund Mach and partly at the Slovak Academy of Science, Bratislava, Slovakia. Study sites were part of the ROCOALPS project (Rodent communities in a changing environment: implications for human health in the Alps).

\section{Funding}

This project was partially funded by Marie Skłodowska-Curie Actions-COFUND TRENTINO: 2009 Call, Incoming Postdoc Project ROCOALPS - Trentino Grant Agreement n. 226,070 (to AK and HCH), by the Slovak Research and Development Agency under contract No. APW -14-0274 (to IB and MD), by the European Union grant FP7-261504 EDENext (to AR) and by the FIRST PhD School of the Fondazione Edmund Mach (to $\mathrm{IB}, \mathrm{AR}$ and $\mathrm{HCH}$ ). This manuscript is catalogued by the EDENext Steering Committee as EDENext 474 (http://www.edenext.eu); the contents of this publication are the sole responsibility of the authors and do not necessarily reflect the views of the European Commission.

\section{Availability of data and materials}

The data supporting the conclusions of this article are included within the article. The sequences were submitted to the GenBank database under accession numbers KX517839-KX517840.

\section{Authors' contributions}

$M D, A K, H C H$ and $A R$ acquired the funding for the field and laboratory work. VT and AK carried out the fieldwork. FR and IB carried out the genetic analysis. MD and IB performed the phylogenetics. VT carried out the statistical analysis. FR and VT drafted the paper. All authors critically reviewed the manuscript. All authors read and approved the final manuscript.

\section{Competing interests}

The authors declare no competing interests.

\section{Consent for publication}

Not applicable.

\section{Ethics approval and consent to participate}

All animal handling procedures and ethical issues were approved by the Wildlife Committee of the Autonomous Province of Trento (Prot. n. 595 issued on 4th May 2011). 


\section{Publisher's Note}

Springer Nature remains neutral with regard to jurisdictional claims in published maps and institutional affiliations.

\section{Author details}

"Fondazione Edmund Mach, Research and Innovation Centre, San Michele all'Adige, TN, Italy. ${ }^{2}$ Slovak Academy of Science, Bratislava, Slovakia. ${ }^{3}$ Masaryk University, Brno, Czech Republic.

\section{Received: 11 April 2017 Accepted: 25 May 2017}

\section{Published online: 14 June 2017}

\section{References}

1. Jahfari S, Coipan EC, Fonville M, van Leeuwen AD, Hengeveld P, Heylen $D_{\text {, }}$ et al. Circulation of four Anaplasma phagocytophilum ecotypes in Europe. Parasit Vectors. 2014;7:365.

2. Rizzoli A, Silaghi C, Obiegala A, Rudolf I, Hubálek Z, Földvári G, et al. Ixodes ricinus and its transmitted pathogens in urban and peri-urban areas in Europe: new hazards and relevance for public health. Front Public Health. 2014:2:251.

3. Bown KJ, Lambin X, Telford GR, Ogden NH, Telfer S, Woldehiwet Z, et al. Relative importance of Ixodes ricinus and Ixodes trianguliceps as vectors for Anaplasma phagocytophilum and Babesia microti in field vole (Microtus agrestis) populations. Appl Environ Microbiol. 2008;74:7118-25.

4. Stuen S, Granquist EG, Silaghi C. Anaplasma phagocytophilum - a widespread multi host pathogen with highly adaptive strategies. Front Cell Infect Microbiol. 2013;3:31.

5. Dumler JS, Choi KS, Garcia-Garcia JC, Barat NS, Scorpio DG, Garyu JW, et al. Human granulocytic anaplasmosis and Anaplasma phagocytophilum. Emerg Infect Dis. 2005;11:1828-34.

6. Dugat T, Lagrée AC, Maillard R, Boulouis HJ, Haddad N. Opening the black box of Anaplasma phagocytophilum diversity: current situation and future perspective. Front Cell Infect Microbiol. 2015;5:61.

7. Ismail N, Bloch KC, MC Bride JW. Human ehrlichiosis and anaplasmosis. Clin lab med. 2010;30:261-92

8. Piccolin G, Benedetti G, Doglioni C, Lorenzato C, Mancuso S, Papa N, et al. A study of the presence of Borrelia burgdorferi, Anaplasma (previously Ehrlichia) phagocytophilum, Rickettsia and Babesia in Ixodes ricinus collected within the territory of Belluno. Italy Vector Borne Zoonotic Dis. 2006;6:24-31.

9. Cinco M, Padovan D, Murgia R, Maroli M, Frusteri L, Heldtander M, et al. Coexistence of Ehrlichia phagocytophila and Borrelia burgdorferi sensu lato in Ixodes ricinus ticks from Italy as determined by $16 \mathrm{~S}$ rRNA gene sequencing. J Clin Microbiol. 1997;35:3365-6.

10. Kauffmann M, Rehbein S, Hamel D, Lutz W, Heddergott M, Pfister K, et al. Anaplasma phagocytophilum and Babesia spp. in roe deer (Capreolus capreolus), fallow deer (Dama dama) and mouflon (Ovis musimon) in Germany. Mol Cell Probes. 2017;31:46-54.

11. Carrade DD, Foley JE, Borjesson DL, Sykes JE. Canine granulocytic anaplasmosis: a review. J Vet Intern Med. 2009;23:1129-41.

12. Stuen S. Anaplasma phagocytophilum (Formerly Ehrlichia phagocitophila) infection in sheep and wild ruminants in Norway. A study on clinical manifestation, distribution and persistence. PhD thesis, Norwegian School of Veterinarian Science, Oslo. 2003.

13. Bjöersdorff A, Bergstrom S, Massung RF, Haemig PD, Olsen B. Erlichiainfected ticks on migrating birds. Emerg Infect Dis. 2001;7:877-9.

14. Sparagano O, George D, Giangaspero A, Špitalská E. Arthropods and associated arthropod-borne diseases transmitted by migrating birds. The case of ticks and tick borne pathogens. Vet Parasitol. 2015;213:61-6.

15. Kiffner C, Vor T, Hagedorn P, Niedrig M, Ruhe F. Factors affecting patterns of tick parasitism on forest rodents in tick borne encephalitis risk areas, Germany. Parasitol Res. 2011;108:323-35.

16. Bown KJ, Lambin X, Ogden NH, Begon M, Telford G, Woldehiwet Z, et al. Delineating Anaplasma phagocytophilum ecotypes in coexisting, discrete enzootic cycles. Emerg Infect Dis. 2009;15:1948-54.

17. Blaňarová L, Stanko M, Carpi G, Miklisová D, Víchová B, Mošanský L, et al. Distinct Anaplasma phagocytophilum genotypes associated with lxodes trianguliceps ticks and rodents in Central Europe. Ticks Tick Borne Dis. 2014;5:928-38.

18. Baráková I, Derdáková M, Carpi G, Rosso F, Collini M, Tagliapietra V, et al. Genetic and ecologic variability among Anaplasma phagocytophilum strains, northern Italy. Emerg Infect Dis. 2014;6:1082-5.
19. Dumler JS. The biological basis of sever outcomes in Anaplasma phagocytophilum infection. FEMS Immunol med Microbiol. 2012;64:13-20.

20. Adams DA, Jajosky RA, Ajani U, Kriseman J, Sharp P, Onweh DH, et al. Summary of notifiable diseases - United States, 2012. MMWR Morb Mortal Wkly Rep. 2014;61:1-121.

21. Zhang L, Liu H, Xu B, Zhang Z, Jin Y, Li W, et al. Rural residents in China are at increased risk of exposure to tick-borne pathogens Anaplasma phagocytophilum and Ehrlichia chaffeensis. Biomed Res Int. 2014;2014:313867.

22. Courtney JW, Dryden LR, Montgomery J, Schneider BS, Smith G, Massung RF. Molecular characterization of Anaplasma phagocytophilum and Borrelia burgdorferi in Ixodes scapularis ticks from Pennsylvania. J Clin Microbiol. 2003:41:1569-73.

23. Reichard MV, Roman RM, Kocan KM, Blouin EF, de la Fuente J, Snider TA, et al. Inoculation of white-tailed deer (Odocoileus virginianus) with Ap-V1 or NY-18 strains of Anaplasma phagocytophilum and microscopic demonstration of Ap-V1 in Ixodes scapularis adults that acquired infection from deer as nymphs. Vector Borne Zoonotic Dis. 2009;9:565-8.

24. Massung RF, Priestley RA, Miller NJ, Mather TN, MI L. Inability of a variant strain of Anaplasma phagocytophilum to infect mice. J Infect Dis. 2003;188:1757-63

25. Liz JS, Anderes L, Sumner JW, Massung RF, Gern L, Rutti B, et al. PCR detection of granulocytic ehrlichiae in Ixodes ricinus ticks and wild small mammals in western Switzerland. J Clin Microbiol. 2000;38:1002-7.

26. Bown KJ, Begon M, Bennett M, Woldehiwet Z, Ogden NH. Seasonal dynamics of Anaplasma phagocytophila in a rodent-tick (Ixodes trianguliceps) system, United Kingdom. Emerg Infect Dis. 2003;9:63-70.

27. Chastagner A, Moinet M, Perez G, Roy E, McCoy KD, Plantard O, et al. Prevalence of Anaplasma phagocytophilum in small rodents in France. Ticks TickBorne Dis. 2016;7:988-91.

28. Kallio ER, Begon M, Birtles RJ, Bown KJ, Koskela E, Mappes T, et al. First report of Anaplasma phagocytophilum and Babesia microti in rodents in Finland. Vector Borne Zoonotic Dis. 2014;14:389-93.

29. Torre I, Arrizabalaga A. Habitat preference of the bank vole Myodes glareolus in a Mediterranean mountain range. Acta Theriol. 2008;53:241-50.

30. Michielin V. II sistema acqua suolo. In: Rapporto sullo stato dell'ambiente 2003. Provincia Autonoma di Trento, Trento 2003; 112.

31. Obiegala A, Pfeffer M, Pfister $K$, Tiedemann $T$, Thiel $C$, Balling $A$, et al. Candidatus Neoehrlichia mikurensis and Anaplasma phagocytophilum: prevalences and investigations on a new transmission path in small mammals and ixodid ticks. Parasit Vectors. 2014;7:563.

32. Svitálková Z, Haruštiaková D, Mahríková L, Berthová L, Slovák M, Kocianová E, et al. Anaplasma phagocytophilum prevalence in ticks and rodents in an urban and natural habitat in south-western Slovakia. Parasit Vectors. 2015;8:276.

33. Sinsky RJ, Piesman J. Ear punch biopsy method for detection and isolation of Borrelia burgdorferi from rodents. J Clin Microbiol. 1989;27(8):1723-7.

34. Massung RF, Priestley RA, Levin ML. Transmission route efficacy and kinetics of Anaplasma phagocytophilum infection in the white-footed mouse, Peromyscus leucopus. Vector Borne Zoonotic Dis. 2004;4:310-8.

35. Randolph SE, Miklisoá D, Lysy J, Rogers DJ, Labuda M. Incidence from coincidence: patterns of tick infestations on rodents facilitate transmission of tick-borne encephalitis virus. Parasitology. 1999;1 18:177-86.

36. Humair PF, Rais O, Gern L. Transmission of Borrelia afzelii from Apodemus mice and Clethrionomys voles to Ixodes ricinus ticks: differential transmission pattern and overwintering maintenance. Parasitology. 1999;118:33-42.

37. Michalik J, Hofman T, Buczek A, Skoracki M, Sikora B. Borrelia burgdorferi s.l.in Ixodes ricinus (Acari: Ixodidae) ticks collected from vegetation and small rodents in recreational areas of the city of Poznań. J Med Entomol. 2003:40:690-7.

38. Paulauskas A, Radzijevskaja J, Rosef O, Turcinaviciene J, Ambrasiene D. Infestation of mice and voles with Ixodes ricinus ticks in Lithuania and Norway. Est J Ecol. 2009:58:112-25.

39. Gray J, Kirstein F, Robertson J. Borrelia burgdorferi sensu lato in Ixodes ricinus ticks and rodents in a recreational park in south-western Ireland. Exp Appl Acarol. 1999;23:717-29.

40. Hanincova K, Schafer S, Etti S, Sewell H, Taragelova V, Ziak D, et al. Association of Borrelia afzelii with rodents in Europe. Parasitology. 2003;1 26:11-20.

41. Siński E, Pawelczyk A, Baker A, Behnke J. Abundance of wild rodents, ticks and environmental risk of Lyme borreliosis: a longitudinal study in an area of Mazury Lakes district of Poland. Ann Agric Environ Med. 2006;13:295-300. 
42. Estrada-Peña A, Osácar JJ, Pichon B, Gray JS. Host and pathogen detection for immature stages of Ixodes ricinus (Acari:Ixodidae) in north-Central Spain Exp Appl Acarol. 2005;37:257.

43. Burri C, Schumann O, Schumann C, Gern L. Are Apodemus spp. mice and Myodes glareolus reservoirs for Borrelia miyamotoi, Candidatus Neoehrlichia mikurensis, Rickettsia helvetica, R. monacensis and Anaplasma phagocytophilum? Ticks Tick Borne Dis. 2014;5:245-51.

44. Krücken J, Schreiber C, Maaz D, Kohn M, Demeler J, Beck S, et al. A novel high-resolution melt PCR assay discriminates Anaplasma phagocytophilum and "Candidatus Neoehrlichia mikurensis". J Clin Microbiol. 2013;51:1958-61.

45. Randolph SE. Patterns of distribution of the tick Ixodes trianguliceps Birula on its hosts. J Anim Ecol. 1975;44:451-74

46. Mysterud A, Byrkjeland R, Qviller L, Viljugrein $H$. The generalist tick Ixodes ricinus and the specialist tick Ixodes trianguliceps on shrews and rodents in a northern forest ecosystem - a role of body size even among small hosts. Parasit Vectors. 2015;16:639.

47. Turner AK, Beldomenico PM, Bown K, Burthe SJ, Jackson JA, Lambin X, et al. Host-parasite biology in the real world: the field voles of Kielder. Parasitology. 2014;141:997-1017.

48. Michaux JR, Kinet S, Filippucci MG, Libois R, Besnard A, Catzfelis F. Molecular identification of three sympatric species of wood mice (Apodemus sylvaticus, A. flavicollis, A. alpicola) in western Europe (Muridae, Rodentia). Mol Ecol Notes. 2001;1:260-3

49. Massung RF, Levin ML, Munderloh UG, Silverman DJ, Lynch MJ, Gaywee JK. Isolation and propagation of the Ap-variant 1 strain of Anaplasma phagocytophilum in a tick cell line. Jour Clin Microbiol. 2007:45:2138-43.

50. De la Fuente J, Massung RF, Wong SJ, Chu FK, Lutz H, Meli M, et al. Sequence analysis of the msp4 gene of Anaplasma phagocytophilum strains. J Clin Microbiol. 2005;43:1309-17.

51. Carpi G, Bertolotti L, Pecchioli E, Cagnacci F, Rizzoli A. Anaplasma phagocytophilum groEL gene heterogeneity in Ixodes ricinus larvae feeding on roe deer in northeastern Italy. Vector Borne Zoonotic Dis. 2009;9:179-84.

52. Tamura K, Stecher G, Peterson D, Filipski A, Kumar S. MEGA6: molecular evolutionary genetics analysis version 6.0. Mol Biol Evol. 2013;30:2725-9.

53. Harris JW, Stocker H. Maximum Likelihood Method. In: Handbook of mathematics and computational Science. New York: Springer-Verlag; 1998. p. 824.

54. Tamura K, Nei M. Estimation of the number of nucleotide substitutions in the control region of mitochondrial DNA in humans and chimpanzees. Mol Biol Evol. 1993;10:512-26.

55. Felsenstein J. Confidence limits on phylogenies: an approach using the bootstrap. Evolution. 1985;39:783-91.

\section{Submit your next manuscript to BioMed Central and we will help you at every step:}

- We accept pre-submission inquiries

- Our selector tool helps you to find the most relevant journal

- We provide round the clock customer support

- Convenient online submission

- Thorough peer review

- Inclusion in PubMed and all major indexing services

- Maximum visibility for your research

Submit your manuscript at www.biomedcentral.com/submit 